\title{
LYDIA KELDAĞ'I ÜZERİNE YENİ BİR DEĞERLENDİRME
}

\author{
A New Evaluation on Lydian Keldăg
}

\section{Hatice KALKAN*}

ÖZ: Antik dönemin Karios kutsal dağı ile aynı yer olarak önerilen Keldağ, Lydia Bölgesinde, Küçük Menderes ovalık alanının batı kesimindeki konumu ve yüksekliği ile stratejik bir öneme sahiptir. Karios Dağı antik yazarlardan Ksanthus ve Eumeles'in kayıtlarında konu edilmektedir. Öte yandan coğrafyacı Strabon tarafından bölgede, ovaya hâkim konumda ve üzerindeki beyaz taştan bir Pers yapısı ile işaret edilen kutsal bir dağ tarifi yapılmakta ancak, yazar tarafından bu dağın Karios olduğuna dair herhangi bir bilgi verilmemektedir. Keldağ Strabon'un bu tarifleriyle oldukça yakın bir uyum içindedir ve yazarın işaret ettiği dağın Keldağ olarak lokalize edilmesi makul bir olasılıktır. Keldağ'ın zirvesinde doğal bir kayalık düzenleme (ateş altarı?) Pers dinî pratiklerine uygunluk göstermesi açısından, Strabon un "kutsal dağ" nitelemesi ile örtüşmekte ve belki buradaki erken dönemlerden beri süregelen dinsel bir kullanıma da vurgu yapılmaktadır. Ancak buradaki asıl soru Keldağ'ın aynı zamanda Karios Dağı olup olmadığıdır. Diğer antik yazarların metinlerinde üzerindeki Zeus Karios Mabedi ile konu edilen Karios Dağı'nın Keldağ olabileceğini söylemek için tatmin edici arkeolojik veriler mevcut değildir ve bu durum bölgede farklı dağ olasılıklarını da tartışmaya açmaktadır.

Anahtar Kelimeler: Karios, Keldağ, Ateş Altarı, Lydia

ABSTRACT: Kelda $\breve{g}$, proposed as the same place as the Karios sacred mountain of the ancient period as strategic importance with its location and height in the western part of the Caystrus valley of the Lydia Region. Some significant information regarding Ancient Mount Karios were recorded by ancient writers Xsanthus and Eumeles. On the other hand, a sacred mountain in the region, dominating the plain and having a white stone Persian structure was description by Strabon, the geographer. But no information regarding that this mountain is Kroios, is given by the author. But the mountain mentioned by Strabon is quite in accordance with the mount and has a strong resemblance to Keldağ. A natural rocky arrangement recently found out (altar of fire?) at the summit of Keldağ coincides with the descriptions of the Strabon such as sacred mountain" and an exedra built by Persians. However, the real question here is whether Keldağ is also Mount Karios.

In the texts of other ancient authors, there is no archaeological data in order to say that the mountain Karios, which is the exact location of the Zeus Karios Shrine is Keldağ. Therefore, this will come up for discussion of other mountain possibilities at the location.

* Doç. Dr., Namık Kemal Üniversitesi, Fen-Edebiyat Fakültesi, Arkeoloji Bölümü, Değirmenaltı Yerleşkesi, Merkez/Tekirdă̆, hkalkan@nku.edu.tr, ORCID: 0000-0002-1678196X

Geliş Tarihi / Received: 10.05.2020

Kabul Tarihi / Accepted: 17.05.2020

Yayın Tarihi / Published: 14.07.2020 
Keywords: Karios, Kelda ğ, Fire Altar, Lydia

Günümüzde üzerinde Orman Bakanlığı'nın yangın gözetleme tesisi bulunan Keldağ'1n deniz seviyesinden yüksekliği 1372 metredir (Şekil 1). Küçük Menderes (Kaystros) ovalık alanında yer alan yükselti 1995 yılında Amerikalı bir ekibin araştırma programı kapsamında ziyaret edilmiş, L. Bengisu tarafından buradaki kalıntılarla ilgili değerlendirmeler bir makalede ele alınmıştır' ${ }^{1}$.

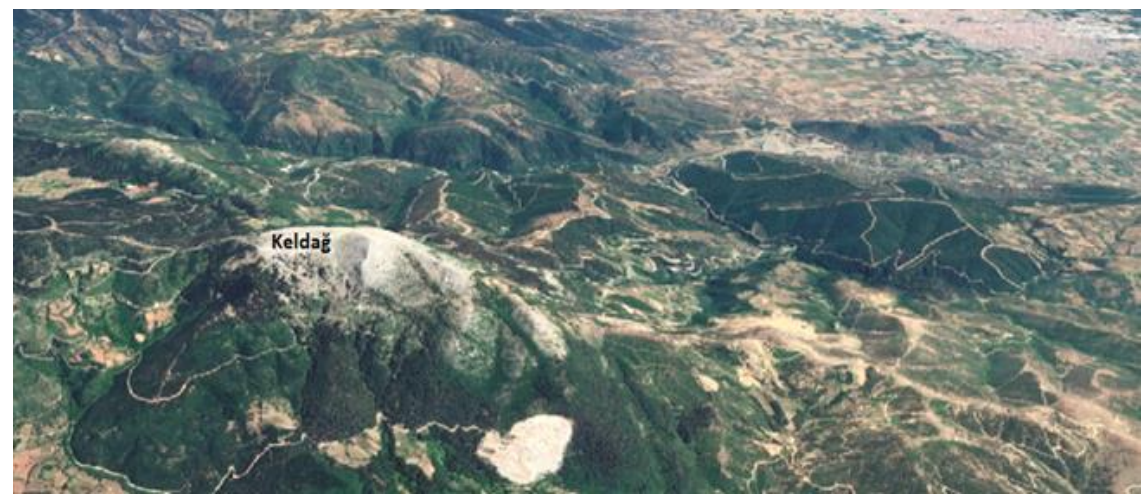

Şekil 1. Keldă̆ ve Ovalık Alan Genel Görünüm

Dik ve oldukça zorlu bir ulaşım yolu olan Keldağ'a tarafımızca yapılan 2017 yılı ziyareti sırasında zirvenin yüzeyinde birkaç kaba seramik parçası dışında herhangi bir buluntuya rastlanmamıştır (Şekil 2).

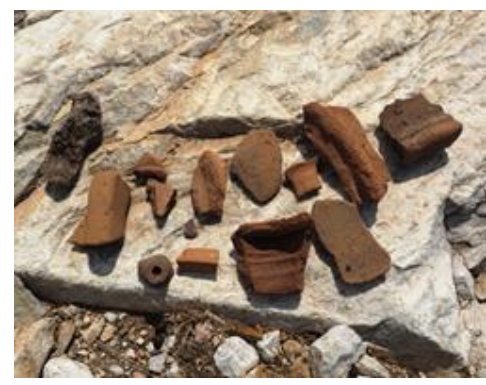

Şekil 2. Çanak Çömlek Parçaları

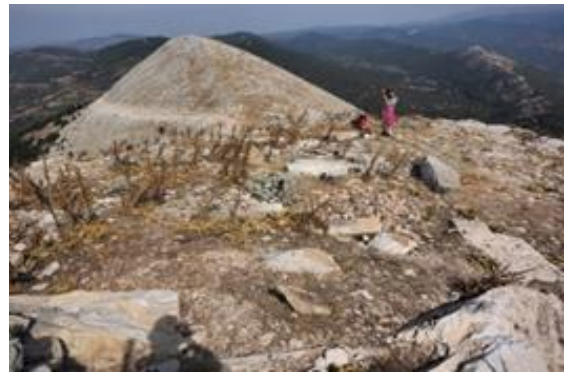

Şekil 3. Kesme Taş Bloklar/Temel İzleri

\footnotetext{
${ }^{1}$ Rose, L., Bengisu, "Research in theTmolus and The Cult of Karios in Lydia: The Survey at Keldağ and Ovacik Agust 1995”, Anadolu, S. 39, 2013, s. 165-197.
} 
Bununla birlikte, Keldağ'ın doğal beyaz kayaçlarından şekillendirilmiş düzgün kesme taş bloklar yüzeyde düzensiz bir şekilde görülebilir durumdadır. Dağın zirvesinde yer alan orman gözetleme kulesinin hemen doğusundaki bu dağınık taş blok sırası $8.20 \times 4.65 \mathrm{~m}$. boyutlarında dikdörtgen bir plan verecek şekilde takip edilebilmektedir (Şekil 3). Keldağ zirvesindeki mevcut olan mimari kalıntıların yanı sıra bu alanın kuzey batı kesiminde, doğal kayalık bir kütlenin yüzeyinde, oyularak şekillendirilmiş bir düzenleme yer almaktadır. Zeminin çok eğimli olması nedeniyle yüzeyinde bir insanın durabilmesini sağlayan düzgün biçimde kesilerek iki basamak oluşturulmuş, bu noktadan başlayan sı̆̆ uzun bir akıtma yolu daha aşağıdaki derin bir çukurla birleşecek şekilde planlanmıştır. Çukurda iz yapmış olan koyu renk farklılı̆̆ı (karbon?) olasılıkla bir sıvının akış yönündeki eğimi takip ederek bu oyukta toplanmış olduğu ve olasilıkla yakıldığı bir kullanıma da işaret etmektedir (Şekil 4).
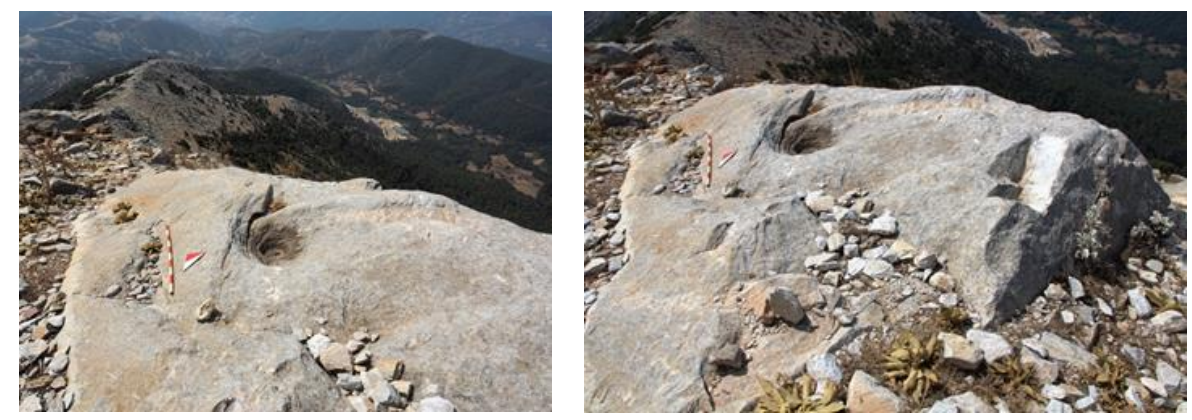

Şekil 4. Kayalık Düzenleme, Ateş Altarı?

Keldağ, ovalık alandan fark edilen beyaz görünümlü zirvesiyle aynı zamanda bir mermer kaynağıdır ve konumlandığı Küçük Menderes Ovasının en stratejik yükseltilerinden biridir. Sardeis ve Ephesos arasında Subatan Yaylası üzerinden uzanan ve kısmen kalıntılarını da saptayabildiğimiz yol rotasının üzerinde önemli bir yere sahiptir. Ayrıca, ovalık kesimle birlikte, doğu batı ve kuzey yönlerinin de izlenebildiği bir konumdadır. Bu açıdan özellikle Pers döneminde ovadaki tehditlere karşı bir haberleşme noktası şeklinde değerlendirilmektedir. MÖ 499 yılında Ephesos ve Sardeis kentleri arasındaki en kısa yol durumundaki bu güzergâhı, Pers idaresine karşı ayaklanan ve satraplık merkezi Sardeis'e ulaşan İonialı ihtilâlcilerin kullanmış olduğu kabul edilir ${ }^{2}$. Perslerin kontrolü altında olduğu düşünülen bu rota Subatan Yaylası yoluyla Tmolos Dağı'nı (Bozdağ) aşarak Sardeis'e

${ }^{2}$ Clive Foss, "Explorations in Mount Tmolus", California Studies in Classical Antiquity, C. XI, 1978, s. 27. 
uzanan antik bir dağ yoludur. Kısmi kalıntılarının günümüzde görülebildiği yolun yakınında yer alan Keldağ'ın Batı Anadolu'nun kaleli güvenlik sistemi içinde önemli bir yeri olduğu söylenebilir. Bölgede son dönemde savunma sistemleri üzerine araştırma yapan bir ekip, yayınlarında Adatepe, Sivrikaya, Kaynaklar, Akçakaya Kalesi ve Belkahve zirvelerinde belirledikleri antik kale kalıntılarını ve buralardaki doğal kayalıklardan elde edilen kesme taş blokların teras düzenlemeleri ve duvar örgüsündeki kullanımlarını büyük ölçüde Hellenistik döneme tarihlemiş durumdadır ${ }^{3}$. Bu araştırmalarda dikkat çekilen bir diğer husus, kalıcı ve geçici olarak düzenlenen tahkimat alanlarındaki taş işçiliğindeki farklılıktır. Buna göre, askerî kamp görümünde (stratopedon) düzenlenen geçici alanlarda bu faaliyet aynı yerden kolaylıkla sağlanan malzemelerle düzensiz bir işçilikle gerçekleştirilmektedir ${ }^{4}$. Keldağ üzerinde surlu bir savunma sistemine ilişkin kalıntılar belirlenemiyor ancak topografik özelliği nedeniyle daha çok bir gözetleme noktası olarak kullanılmış olduğu söylenebilir. Bu açıdan Keldağ üzerindeki kesme taş blokların, yukarıda değinilen geçici askerî kamp (stratopedon) kullanımına uygunluğu içinde yeniden ele alınması önemli bir husustur.

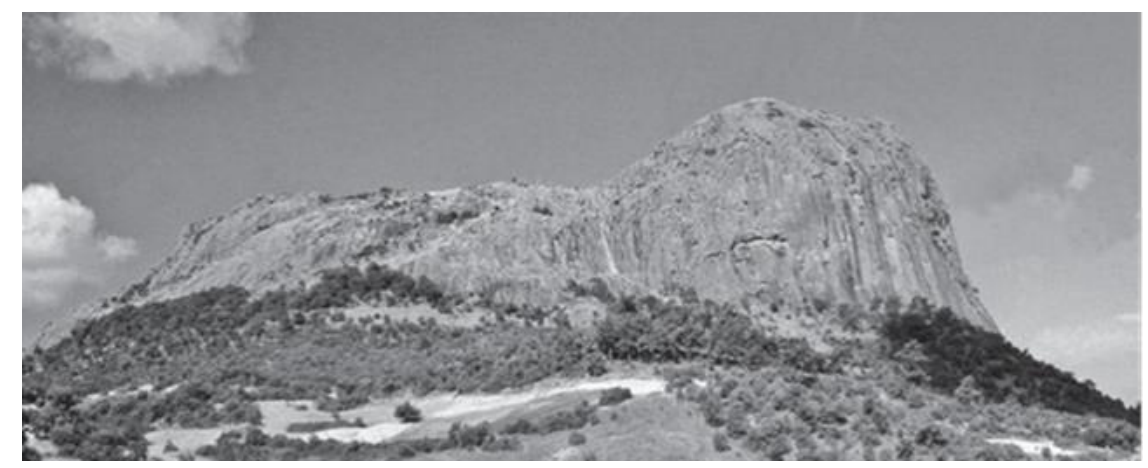

Şekil 5. Şahankaya, Genel Görünüm (C. H. Roosevelt, age., şek. 5.10)

Stratejik geçitlerde bu türde taş duvar işçiliğine sahip Hellenistik Çă kalelerine Ödemiş/Balabanl1, Kiraz/Yağlar, Karaburç ve Beydağ/Eğridere'de de rastlanır. Bu kaleler/karakollar Ephesos'tan Hierapolis-Tripolis'e ve Ephesos'tan Philadelphia'ya uzanan yollara hâkim stratejik noktalarda kurulmuşlardır. Bölgede Küçük Menderes (Kaystros) Ovasının antik dönemde güvenliğinin kontrol altında tutulmasını sağlayan benzer bir yer

${ }^{3}$ Hakan Göncü - Burak Yolaçan - Akın Ersoy, "Smyrna İzmir Kırsalında Yer Alan Bazı Savunma Yapıları Üzerine Bir Değerlendirme", TÜBA-KED, S. 19, 2019, s. 24.

${ }^{4}$ H. Göncü - B. Yolaçan - A. Ersoy, agm.,s. 13. 
Aydın (Messogis) Dağları üzerinde Güme Dağı'nda görülmektedir. Söz konusu yerde Yörükgediği'nde ele geçen buluntular buranın stratejik önemini ortaya koyacak niteliktedir. MÖ 4. yüzy1la tarihlenen bir Ephesos sikkesinin ön yüzündeki Kaystros Ovasının tasviri bu alandaki Pers kontrolünün somut bir kanıtı olarak değerlendirilmektedir ${ }^{5}$. Diğer bir örnek Şahantepe olarak bilinen kayalık kütle üzerindedir (Şekil 5). Kuzey Lydia'nın büyük ölçüde gözlenebildiği, iki yükseltiden meydana gelen bu kayalığın zirvesinde bir Pers ateş altarı da tespit edilmiş durumdadır ${ }^{6}$. Roosevelt, Şahankaya'daki Pers unsurlarını ve ateş altarının varlığını buradaki Pers kökenli Maibozanoi halkına atıfla askerî koloni, ya da bir garnizon olasılığı içinde açıklamaktadır. Araştırmacı, ateş altarı ile ilgili, bölgeye tamamen yabancı olan Pers askerlerine, aşina oldukları bir kutsal alanın yaratılmış olabileceği yorumunda bulunmuştur Burada dikkat çekilmesi gereken husus, Perslerin kayalık zirvelerde askerî amaçlı kullanımlarının beraberinde, dinsel etkinlikler için pratik düzenlemelerle buralarda ateş altarları oluşturma eğilimleridir (Şekil 6).

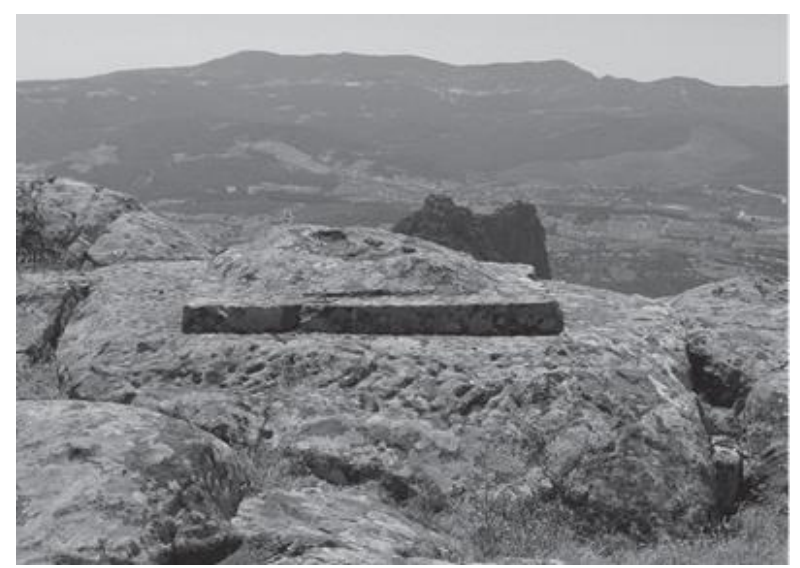

Şekil 6. Şahankaya - Ateş Altarı (C. Roosevelt, age., şek. 5.12)

Orta Anadolu'daki Amasya Harşena Kalesi'nde yer alan ve bir sikke üzerinde de tasvir edilen ateş altarı, kale üzerindeki kayalık bir alanda tespit

\footnotetext{
${ }^{5}$ Şükrü Tül, Artemis Yolu Üstünde İlkçağ Kenti Hypaipa, Ödemiş Belediyesi Yıldız Kent Arşivi ve Müzesi Yayını, 1. Baskı, İzmir, 2014, s. 57.

${ }^{6}$ Christopher Roosevelt, Gyges'ten Büyük İskender'e Lydia Arkeolojisi, Çev. H. Gültekin

Çatak, Koç Üniversitesi Yayınları, İstanbul, 2017, s. 164
} 
edilmiş durumdadır ${ }^{7}$. Kalede, kayalar şekillendirilerek bir ateş altarı elde edilmiştir (Şekil 7).

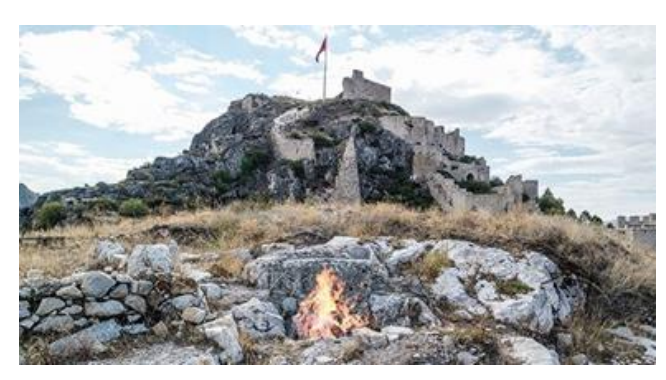

Şekil 7. Amasya, Ateş Altarı

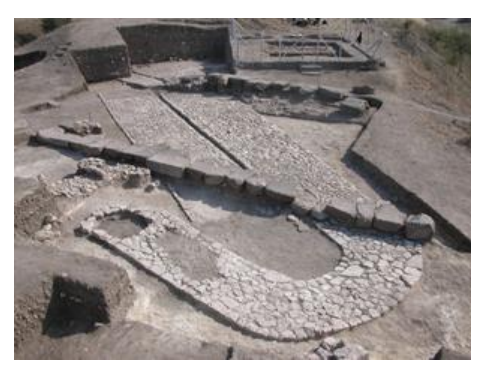

Şekil 8. Daskyleion, Kült Yolu

Verilen örneklerle benzer bir görünüm yansıtan, Keldağ'in zirvesindeki doğal kayalık alandaki düzenleme, Anadolu'da Pers dinî pratiklerinin açık alanlarda ve mimari bir arayış gerektirmeyen uygulamaları içinde ele alınabilecek niteliktedir. Pers tapım pratiklerinin, Anadolu'da Kayseri Bünyan örneğinde olduğu gibi taşınabilir ateş altarları ya da Daskyleion (Şekil 8) ve Oluz Höyük'te olduğu gibi tabakalı merkezlerde rastlandığı haliyle tabanda çukurlaştırılmış düzenlemeler dâhilinde gerçekleştirilmiş olduğu dikkat çekmektedir ${ }^{8}$. Bu merkezlerde yer alan her iki pratik, ateşin korunaklı bir derinlik içinde sönmesinin önlendiği bir çözümü ortaya koymaktadır 9 . Öte yandan İran coğrafyasında Pers döneminin erken evresine tarihlenen Med merkezi Nuş-i Can Tepe'de yer alan üç tapınaktan birindeki in situ halinde saptanan ateşgede düzenlemesi (Şekil 9) ise kapalı bir mekânda nadir bir örnek olarak karşımıza çıkmaktadır ${ }^{10}$.

${ }^{7}$ Şevket Dönmez, "Yeni Arkeolojik Gelişmeler Işı̆̆ında Orta Karadeniz Bölgesi Demir Çağı Kültürüne Genel Bir Bakış", Anadolu Araştırmaları, S. 19, 2010, s. 155.

8 Tomris Bakır, "Daskyleion (Tyaiy Drayahya) Hellespontine Phrygia Bölgesi Akhaemenid Satraplığı”, Anadolu, S. 25, 2004, s. 7.

9 Şevket Dönmez, Amasya Oluz Höyük, Oluz Höyük Kazı Sonuçları Serisi 2, Kuzey Orta Anadoluda Bir Akhaimenid (Pers) Yerleşmesi, 2009-2013 Dönemi Çalışmaları Genel Değerlendirmeler ve Ön Sonuçlar, Amasya Valiliği Yayınları, 2. Baskı, İstanbul, 2017, s. 215.

${ }^{10}$ Michael Roaf - David Stronach, "Tepe Nush-i Jan,1970:Second Interim Report”, Iran Journal of the British Institute of Persian Studies, C. XI, S. 1, 1973, s. 136. 


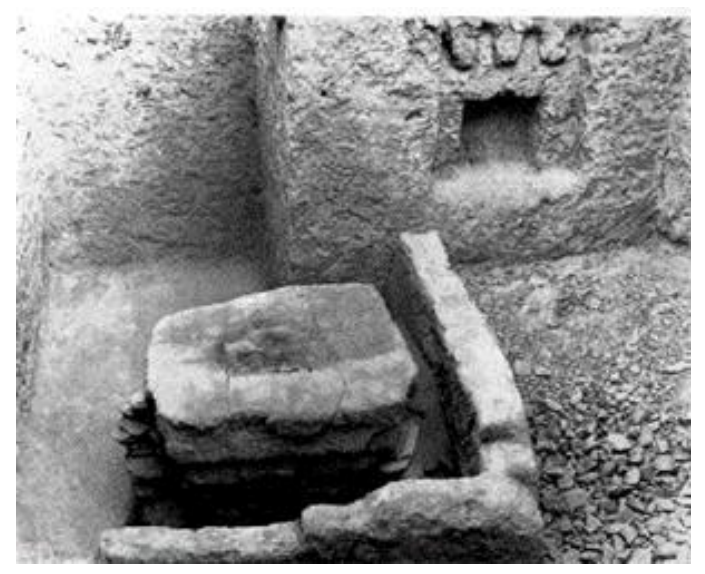

Şekil 9. Nuş-i Can Tepe, Ateş Sunağ

Anadolu'da her ne kadar Pers tanrıçası Artemis Anaitis ya da Persike tapımları, Roma Döneminde tapınak yapıları ve kült heykelleri ile sürdürülmüş olsa da bunlar geç dönem örnekleridir ve bölgedeki Pers rahiplerinin bu kült geleneğine katkılarının bu evrede de halen devam ettiğini göstermektedir. Nitekim Roma Döneminde Keldağ'ın yakın çevresinde Hypaipa ve Hierocaeseria antik kentlerinde Anadolu-Pers kimlikli Artemis Anaitis tapınaklarının varlığ sikkeler üzerinde görülmektedir. Roma Dönemi antik yazarlarından Pausanias (MS 2. yüzyıl) buradaki bir Pers rahibinin (magos) yaktığı ateşten ve Hellenlerin bilmedikleri dildeki dualarından kayıtlarında söz ederken, aynı zamanda Hypaipa ve Hierocaeseria'daki tapınaklarına da değinmiştir:

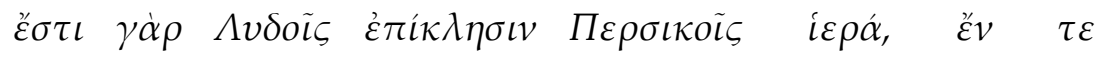

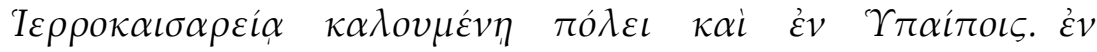

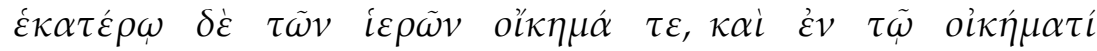

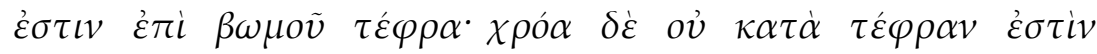
$\alpha \hat{v} \tau \tilde{\eta} \tau \dot{\eta} v \ddot{\alpha} \lambda \lambda \eta \dot{v}$.

Lydialı Perslerin Hierocaesareia ve Hypaepa şehirlerinde kutsal alanlart ve mekânlart vardır ve her birinde, üzerinde küllerin bulunduğu sunaklar mevcuttur. Fakat bu küllerin rengi alışılmış olanlardan değildir (Pausanias V. 27, 5.).
} 


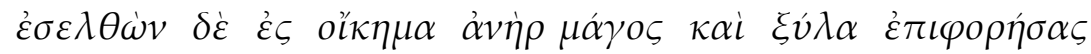

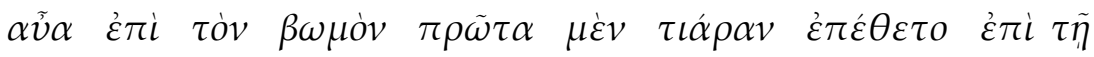
$\kappa \varepsilon \varphi \alpha \lambda \tilde{\eta}, \quad \delta \varepsilon \dot{v} \tau \varepsilon \rho \alpha \quad \delta \dot{\varepsilon} \quad \dot{\varepsilon} \pi i \kappa \lambda \eta \sigma \iota$ ótov $\delta \dot{\eta} \quad \theta \varepsilon \tilde{\omega} v \quad \dot{\varepsilon} \pi \alpha \dot{\alpha} \delta \varepsilon \iota$ $\beta \dot{\alpha} \rho \beta \alpha \rho \alpha \quad \kappa \alpha i \quad o \dot{v} \delta \alpha \mu \tilde{\omega} \varsigma \quad \sigma v v \varepsilon \tau \dot{\alpha} \quad{ }^{\circ} E \lambda \lambda \eta \sigma \iota . \quad \dot{\varepsilon} \pi \alpha \dot{\alpha} \delta \varepsilon l \quad \delta \dot{\varepsilon}$

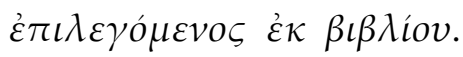

Kutsal odaya giren magos sunak üzerine kuru odun birakır ve hemen ardından kafasına tiarasını geçirir daha sonra ise Hellenlerin anlamadı $\breve{g}$ yabancı bir dilde bir duayı kitaptan okumaya başlar (Pausanias V. 27, 6.).

Pausanias'ın verdiği bilgilerle öğrendiğimiz ateş ayini ve bölgedeki Roma Dönemi sikkeleri üzerindeki yansımalarıla Hellenleşmiş Pers tanrıçası Anaitis'in varlığı, geç bir evrede Perslerin Anadolu'da siyasi olmasa da dinsel bir etkinlik içinde varlıklarını sürdürdüklerini ortaya koymaktadır. $\mathrm{Bu}$ inanç ortaklığ 1 aslında Perslerin Lydia'ya ilk gelişlerinden itibaren benimsenmiş ve Roma Dönemi içlerine kadar sürdürülmüş olmalıdır ${ }^{11}$. Lydia Bölgesinde, Anaitis inancı dışında, Zeus Karios kültünün varlığına dair bilgiler ve Karios Dağı ile ilgili tarifler antik kayıtlarda mevcuttur Korinthoslu Eumeles'in (MÖ 8. yüzyıl) "Zeus'un doğum yeri Sardes'in batısında ve Tmolos'un üzerindeki bir zirvede"12, ve Lydialı Tarihçi Ksanthus'un (MÖ 5. yüzyıl ortas1) "Torrhebia mevkiinde Karios adlı bir dăg ve üzerinde Karios mabedi var", biçimindeki kayıtlarda geçen bilgileri kanıtlamaya yönelik arkeolojik bulguların değerlendirildiği yayınlar söz konusudur $^{13}$. L. R. Bengisu ${ }^{14}$ Tmolos Dağları'nın (Bozdağlar) uzantısı durumundaki zirve üzerindeki kalıntı ve buluntulardan hareketle Keldağ'ın antik dönem yazarlarınca hem Zeus Karios'un doğum yeri, hem de üzerinde Zeus Karios tapınağının bulunduğuna işaret edilen Karios Dağı ile aynı yer olduğunu önermektedir ${ }^{15}$. Eumeles ve Ksanthus'un tarif ve anlatımlarına ek olarak öneri için dayanak gösterilen bir başka antik yazar coğrafyacı Strabon'dur (MÖ 1. yüzyıl-MS 1. yüzyı1). Kayıtlarında "ovalık alana hâkim,

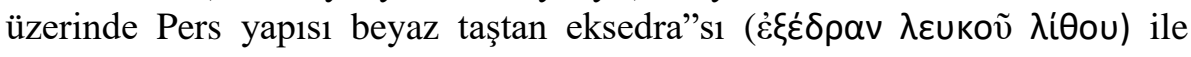
dikkat çektiği yükselti Keldağ’ın günümüzdeki görünümü ve kalıntıları ile

${ }^{11}$ Veli Sevin, "Batı Anadolu'nun Az Bilinen Antik Bir Kenti Hypaipa Tarihi Üzerine Bir Araştırma", Tarih Dergisi, S. 28/29, 1974, s. 44.

12 Felix Jacoby, Die Fragmente der Griechischen Historiker, II-A, Leiden, 1986, s. 340, frg. 15 .

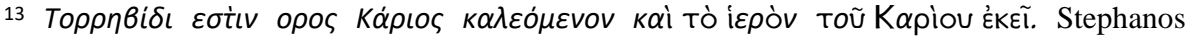
Byzantinos, Ethnica, s. 629.

${ }^{14}$ L. R. Bengisu, agm., 1996, s. 3.

${ }^{15}$ Bk. Nuran Şahin, Zeus'un Anadolu Kültleri, İstanbul, 2001, s. 68-69. 
büyük ölçüde benzerlik içindedir. Ancak yazar, Karios adı ya da Zeus ile bağlantılı hiç bir bilgiyi bu aktarımlara dahil etmemiştir. Bu nedenle yazarın kutsal bir dağ olduğuna vurgu yaptığı ve tarif ettiği yükselti ile ilgili sadece Pers yapıs1 bir eksedrayı kayda geçirmiş olması, diğer antik dönem yazarlarının Karios Dağı hakkındaki kayıtlarının, farklı dağ yükseltilerine işaret etmiş olabileceği bir olasılığı güçlendirmektedir ${ }^{16}$. Nitekim, L. Robert, antik kaynaklarda Torrhebia olarak geçen yeri Gölcük Gölü olarak lokalize etmektedir ${ }^{17}$. Bu haliyle bakıldığında Torrhebia mevkinin yakınında yer alan ve olasılıkla bir kült geleneğine işaret eden Ovacık'taki tapınak kalıntılarının varlığ 1 , bu alanda yaklaşık iki bin metre yüksekliğe erişen Bozdağ zirvesinin Karios olma olasılığını, antik kayıtlara da uygunluğu açısından oldukça güçlendirmektedir ${ }^{18}$ (Şekil 10 ).

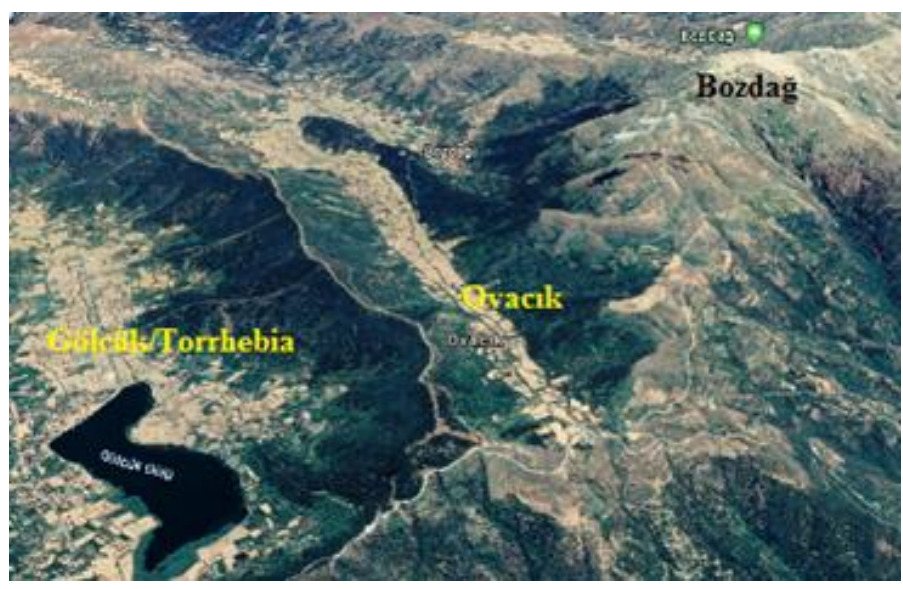

Şekil 10. Torrhebia, Ovacık, Bozdağ

Kayıtlar aracılığı ile Keldağ'da varlığından haberdar olduğumuz eksedra, kavramsal olarak, bir gözetleme kulesi olabileceği yönündeki görüşlerin yanında, arkaik bir tapınak olasılığı içinde de ele alınmıştır ${ }^{19}$. Dikdörtgen temel seviyesinde izlenen taş blok kalıntıları, bu değerlendirmelerde bir

\footnotetext{
${ }^{16}$ Strabon, 13.4.5.

${ }^{17}$ Louis Robert, Villes D'Asie Mineure, Études de géographie ancienne, Paris,1962, s. 314315; Rose Lou Bengisu, "Torrhebia Limne”, Arkeoloji Dergisi, C. V, S. 2, 1993, s. 33-43.

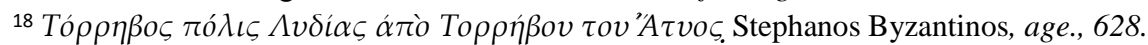

19 Rose Lou Bengisu, "Lydian Mount Karios", Kybele,Attis \&Related Cults, Essays in Memory of M. J. Vermaseren, Religions in The Graeco-Roman World, C. 31,1996, s. 2; Elspeth R.M. Dusinberre, Aspects of Empire in An Achaemenid Sardis, Cambridge, 2003, s. 72.
} 
tapım platformu şeklinde önerilmiş ve antik kaynaklardaki bilgilerin onaylanması amaçlanmıştır (Şekil 11).

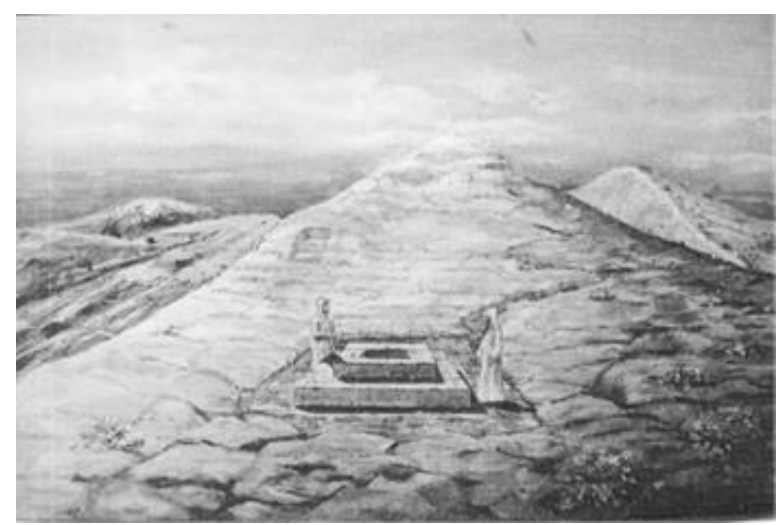

Şekil 11. Keldağ Üzerinde Önerilen Kült Alanı (Bengisu agm., Fig.11-A)

Ancak Persler'in Anadolu kült pratikleri içinde mimariye dayalı böyle bir geleneğe sahip olduğunu başka örneklerle belirleyemiyoruz. Bu nedenle taş blokların bir tapım platformuna ait olabileceği yönündeki tespitler, bu blokların yukarıda örnekleri verilen ve bu tür zirvelerdeki askerî amaçlı düzenlemelerin birincil yap1 elemanları olmaları bakımından yeniden ele alınmalarını gerektirmektedir. Ayrıca, Keldağ'dan toplanmış olan ve Ödemiş Müzesinde muhafaza edilen küçük buluntular, burada olası bir Karios kültüne işaret edecek, bu görüşü güçlendirecek görünümden oldukça uzaktır. Buluntular arasındaki günlük seramik kap parçaları, ağırşaklar ve omphaloslu dip parçaları, burada sadece Lydia, Pers, Hellenistik ve Roma dönemlerindeki küçük ölçekli insan hareketliliğini belgeleyen verilerdir.

Tarihî coğrafya açısından önemli bir yükselti olan Keldağ için önerilen Karios olma olasılığına dair Tmolos dağ silsilesi üzerinde daha ayrıntılı bir araştırma yapılması gerektiği söylenebilir. Kanımızca Bozdağların, Sardes'e Subatan yaylası ve Çamyayla üzerinden uzayan antik güzergahlarının kuzey yönünde detaylı araştırılması gerçekleşmeden bu konuda kesin sonuçlara varmak mümkün görünmemektedir ${ }^{20}$. Ayrıca Ovacık civarında yapılan tespitlerde tapınak kalıntılarıyla karşılaşılmıştır. Erken bir evreden itibaren burada bir kült alanının varlığından söz edilebilir. Nitekim L. Robert'in antik metinlerde geçen Torrhebia'yı Gölcük şeklinde lokalize etmiş olması ve antik metinlerde de Karios Dağı'nın Torrhebia yakınlarındaki konumu ve

${ }^{20}$ Bk. Recep Meriç, Das Hinterland von Ephesos Archaeologisch-Topografische Forchungen im Kaystros, Wien, 2009,103-105. 
üzerindeki Karios Tapınağı'na yapılan atıflar için önerilebilecek Karios Dağı olasılığı için, Keldağ'ın daha doğusundaki bir kesime bakılması isabetli olacaktır (Şekil 12). Bu kesim yine antik kayıtlarda geçen ve Sardes'in yukarılarında Tmolos'un zirvesinde tarif edilen yerle de büyük ölçüde örtüşmektedir.

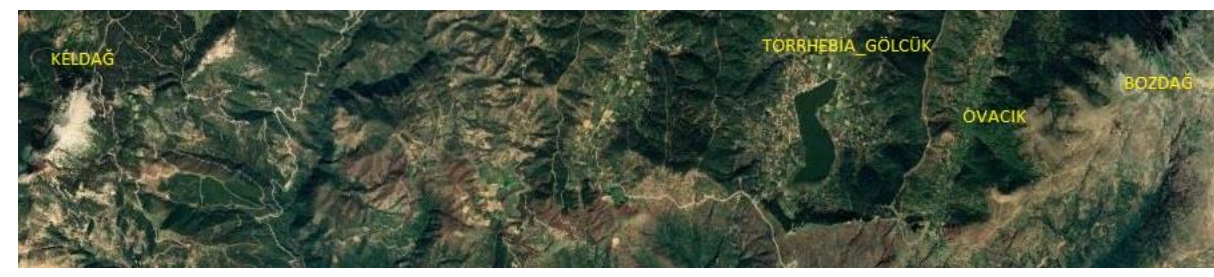

Şekil 12. Keldağ'ın Torrhebia, Ovacık ve Bozdağ'a mesafesi ve konumu

\section{KAYNAKÇA}

\section{Antik Kaynaklar}

Pausanias, Description of Greece, Çev. W. H. S. Jones, Cambridge Harvard University Press, 1926.

Stephani Byzantii, Ethnicorum Quae Supersunt (Ex. Rec. Avgusti Meinekii) Berolini, 1849.

Strabon, Geographica, http://www.perseus.tufts.edu

\section{Modern Kaynaklar}

Bakır, Tomris, "Daskyleion (Tyaiy Drayahya) Hellespontine Phrygia Bölgesi Akhaemenid Satraplığı", Anadolu, S. 25, 2004, s. 1-26.

Bengisu, Rose Lou, "Lydian Mount Karios", Ed. R. Van Den Broek, H. J. W. Drijvers, H. S. Versnel, Kybele, Attis \& Related Cults, Essays in Memory of M.J. Vermaseren, Religions in The Graeco-Roman World, C. 31, Leiden, New York, Köln, 1996, s. 1-16.

Bengisu, Rose Lou, "Research in theTmolus and The Cult of Karios in Lydia: The Survey at Keldağ and Ovacık, Agust 1995”, Anadolu, S. 39: 2013, s. 165197.

Bengisu, Rose Lou, "Torrhebia Limne", Arkeoloji Dergisi, C. V, S. 2, 1993, s. 3343.

Dönmez, Şevket, "Yeni Arkeolojik Gelişmeler Işı̆̆ında Orta Karadeniz Bölgesi Demir Çağ 1 Kültürüne Genel Bir Bakış", Anadolu Araştırmaları, S. 19, 2010, s. 137-196. 
Dönmez, Şevket, Amasya Oluz Höyük, Oluz Höyük Kazı Sonuçları Serisi 2, Kuzey Orta Anadolu'da Bir Akhaimenid (Pers) Yerleşmesi, 2009-2013 Dönemi Çalışmaları Genel Değerlendirmeler ve Ön Sonuçlar, Amasya Valiliği Yayınları, 2. Baskı, İstanbul, 2017.

Dusinberre, Elspeth, R. M., Aspects of Empire in An Achaemenid Sardis, Cambridge University Press, Cambridge, 2003.

Foss, Clive "Explorations in Mount Tmolus", California Studies in Classical Antiquity, C. XI, 1978, s. 21-60.

Göncü, Hakan - Yolaçan, Burak - Ersoy, Akın, "Smyrna İzmir Kırsalında Yer Alan Bazı Savunma Yapıları Üzerine Bir Değerlendirme”, TÜBA-KED, S. 19, 2019, s. 11-28.

Jacoby, Felix, Die Fragmente der Griechischen Historiker,II-A, Leiden, 1986.

Meriç, Recep, Das Hinterland von Ephesos Archaeologisch-Topografische Forchungen im Kaystros, Wien, 2009.

Roaf, Michael - Stronach, David, "Tepe Nush-i Jan,1970:Second Interim Report", Iran Journal of the British Institute of Persian Studies, C. XI, S. 1, 1973, s.129-140.

Robert, Louis, Villes d'Asie Mineure. Études de géographie ancienne, Paris, 1962.

Roosevelt, Christopher, H., Gyges'ten Büyük İskender'e Lydia Arkeolojisi, Çev. H. Gültekin Çatak, Koç Üniversitesi Yayınları, İstanbul, 2017.

Sevin, Veli, "Batı Anadolu'nun Az Bilinen Antik Bir Kenti Hypaipa Tarihi Üzerine Bir Araştırma", Tarih Dergisi, S. 28/29, 1974, s. 41-53.

Şahin, Nuran, Zeus'un Anadolu Kültleri, İstanbul, 2001.

Tül, Şükrü, Artemis Yolu Üstünde İlkçağ Kenti Hypaipa, Ödemiş Belediyesi Yıldız Kent Arşivi ve Müzesi Yayını, 1. Baskı, İzmir, 2014. 